\title{
INTELIGÊNCIA ARTIFICIAL E O ENSINO COM COMPUTADOR
}

\author{
Maria Lucia Pozzatti Flôres \\ Rosa Maria Vicari
}

\section{Resumo}

Com o uso do computador como ferramenta educacional, o professor faz com que seu aluno tenha uma motivação a mais para aprender um conteúdo. Mas os softwares educacionais baseados no modelo educacional comportamentalista (CAI) tem uma desvantagem, pois o professor é a figura central do processo e o aluno é uma figura passiva, onde a função do aluno é compreender os conteúdos passados pelo professor e após responder as questões relacionadas a esse conteúdo. As técnicas de Inteligência artificial proporcionam a possibilidade de dispor de computadores mais autônomos, modificando o tipo de interação homem-máquina, afetando o ensino. Estas técnicas além de permitir a cooperação dos estudantes durante a resolução de problemas, oferecem orientação e informações adicionais.

Palavras chave - Inteligência artificial; ensino; computador.

\begin{abstract}
The use of computers as an educational tool gave to the teacher the possibility to offer the student a new motivation when learning a new contents. Use of educational softwares based on the comportamental model (CAI) have a disadvantage: the teacher is the central point of process and the student is a passive element, his function is only understand the contents and after should answer questions related to that. The IA techniques may offers the chance to use computers with more self-processing capabilities, changing the type of man-machine interaction, thus affecting the learning process. That techniques, beyond the fact that they allows the cooperation of the students in solving problems, can offers additional informations and orientation.
\end{abstract}

Keywords - Artificial inteligency; learning; computer.

\section{1-Introdução}

A partir da década de 50 a Informática na Educação passa a ser um assunto presente em qualquer ambiente de pesquisa em ensino. Pode-se dizer que quase todos os professores, em qualquer nível da educação brasileira, já ouviram falar que a Informática tem vários usos possíveis no processo ensino-aprendizagem, e que tem um enorme potencial enquanto ferramenta educacional. Sabe-se que alguns utilizam computadores fora da sala de aula, na preparação de textos, provas e em pesquisas escolares, e destes, alguns o utilizam inclusive como recurso didático, fazendo o aluno trabalhar diretamente com o computador; assim como existem professores que sequer tiveram acesso a esse tipo de máquina.

Com o uso do computador, o professor faz com que seu aluno alcance maior autonomia e que aprenda a aprender utilizando-se das ferramentas da Informática. Ele utiliza o potencial de comunicação, visualização, experimentação e interatividade do computador. 
Como ferramentas computacionais voltadas para a educação foram desenvolvidos os softwares educacionais chamados CAI - Instruções Assistidas por Computador. Esta categoria de software é baseada no modelo educacional comportamentalista, onde o professor é a figura central do processo ensino-aprendizagem e o aluno é uma figura passiva, a qual deve compreender os conteúdos passados pelo professor para num segundo momento responder as questões relacionadas ao conteúdo visto. Usualmente, estes sistemas geravam conjuntos de problemas projetados para aumentar o desempenho do estudante em domínios baseados em habilidades, como aritmética e recuperação de vocabulário. Nestes sistemas, a instrução não era individualizada para as necessidades do estudante. A proposta era apresentar um problema ao estudante, registrar a resposta e avaliar seu desempenho. As decisões sobre como o estudante deveria navegar através do material era baseada em árvores de decisão. A sequiência de perguntas e respostas era dirigida pelos acertos e erros dos estudantes, não sendo consideradas suas habilidades individuais. Mas, segundo Pianesso apud JESUS (2004) os softwares que se baseiam no modelo comportamentalista apresentam alguns pontos negativos:

- O aluno é controlado pelo software; não é uma figura ativa no processo ensino-aprendizagem;

- O aluno é direcionado a tomar algumas atitudes frente a estímulos apresentados;

- Não há uma preocupação com o processo de raciocínio e aprendizado do aluno;

- São utilizados artifícios de reforço como: notas e elogios.

Para permitir um ensino-aprendizagem personalizado, notou-se a necessidade de inserir "inteligência" nos softwares educacionais. Com isso, as técnicas de Inteligência Artificial (IA) começaram a serem aplicadas nos softwares desta categoria. Os primeiros sistemas educacionais que apresentaram um certo grau de "inteligência" foram os chamados ICAI - Inteligent CAI.

Giraffa (1999) (p.17) afirma que : "Acrescentar um I à sigla CAI não significa apenas agregar técnicas de IA para a construção de sistemas tutores, mas inclui trabalhar de forma interdisciplinar com as conquistas que outras áreas de pesquisa obtiveram em relação ao conhecimento da comunicação inteligente, tais como os avanços da psicologia e da pedagogia”.

Atualmente esta interdisciplinaridade vem sendo aplicada nos chamados Sistemas Tutores Inteligentes (STIs). Estes sistemas pertencem à categoria dos softwares educacionais que se baseiam na aprendizagem interativa. Assim, o aluno passa a ser o centro do processo ensino-aprendizagem, deixando de ser passivo e tornando-se um ser ativo no processo, além de tornar relevante o seu conhecimento atual e as suas características de aprendizado. Por este motivo, existe uma preocupação em gerar STIs capazes de interagir com o aluno, a fim de gerar o modelo cognitivo desse aluno, porque através do modelo gerado será possível selecionar e aplicar a técnica pedagógica mais adequada.

\section{2-O computador na educação}

Valente (1993) classifica os usos do computador na Educação, em dois pólos: 
Pólo 1 - Máquina de ensinar, com raízes nas instruções programadas tradicionais. Classificam-se como tutoriais ou exercício-e-prática. Inclui aí os jogos educacionais e a simulação.

Pólo 2 - Uso de linguagem computacional (LOGO, basic, pascal) ou mesmo o processador de texto. Assim, temos o computador como ferramenta (o que inclui aplicativos como processador de texto ou planilha eletrônica, utilizáveis pelo aluno ou pelo professor), como auxiliar na resolução de problemas, na produção de música, no controle de processos (coleta de dados) ou como comunicador (e-mail, sintetizadores de voz para cegos). Valente afirma que:

"a implantação da Informática na Educação consiste basicamente em quatro ingredientes: o computador, o software educativo, o professor capacitado para usar o computador como ferramenta intelectual e o aluno" (p.3), e que "o ensino pelo computador implica que o aluno, através da máquina, possa adquirir conceitos sobre praticamente qualquer domínio. Entretanto, a abordagem pedagógica de como isso acontece é bastante variada, oscilando entre dois grandes pólos. [...] Num lado, o computador, através do software, ensina o aluno. Enquanto no outro, o aluno, através do software, 'ensina' o computador" (p.3). (1995):

Outra classificação dos usos do computador na Educação é sugerida por Bonilla

- Como máquina de ensinar (exercício e prática ou tutorial);

- Como tutor inteligente (programas com inteligência artificial que se adaptem ao ritmo de desenvolvimento do estudante-usuário);

- Como ferramenta intelectual (simuladores, jogos, editores de texto, multimídia, solução de problemas).

Bonilla (1995) traz questões como o fato de que

"as aulas de Informática não podem estar dissociadas das demais aulas" (p. 67) ou "... para que um software promova realmente a aprendizagem deve estar integrado ao currículo e às atividades de sala de aula, estar relacionado àquilo que o aluno já sabe e ser bem explorado pelo professor. O computador não atua diretamente sobre os processos de aprendizagem, mas apenas fornece ao aluno um ambiente simbólico onde este pode raciocinar, elaborar conceitos e estruturas mentais, derivando novas descobertas daquilo que já sabia” ( p. 68)

Oliveira (1997) faz a classificação entre quatro possibilidades:

- Instrução programada;

- Simulações;

- Aprendizagem por descoberta (LOGO);

- Pacotes Integrados (aplicativos).

O mesmo autor destaca como usos de maior potencial as simulações (como complemento a experimentos de laboratório, e não como substituto a eles) e o uso de aplicativos. Considera que o uso do computador na realização de instruções programadas ou tutoriais não representa nenhum avanço pedagógico, apesar de apresentar maior motivação para aprender um conteúdo, quando comparado a uma atividade semelhante feita sem o computador. Quanto ao LOGO, ele considera seu uso restrito às séries iniciais e dependente de uma formação e implantação com maiores recursos, incluindo trabalho conjunto para o planejamento, de profissionais da área da Informática, pedagogia e psicologia. 
Uma parcela significativa da Informática Educativa é definida pelo uso de softwares específicos. Estes softwares podem ser construídos segundo as mais variadas tecnologias, filosofias e objetivos. E podem ser produzidos por professores, pesquisadores, grandes empresas de software ou pequenas empresas especializadas.

Brandão (1998) e Rocha et al (1993) apresentam metodologias e modelos para avaliação de software educacional. Segundo Rocha et al (1993) os critérios podem ser classificados em três dimensões:

\section{Dimensão 1 - Objetivos do software:}

- Confiabilidade conceitual (fidedignidade e integridade);

- Confiabilidade na representação (legibilidade e manipulabilidade);

- Utilização (manutenibilidade, operacionabilidade, portabilidade, reutilizabilidade, eficiência, rentabilidade e avaliabilidade).

\section{Dimensão 2 - Categorização das aplicações da Informática na Educação:}

- geração de conhecimento;

- disseminação do conhecimento;

- gerenciamento da informação.

\section{Dimensão 3 - Classificação dos ambientes de aprendizagem:}

- Softwares aplicativos;

- Micromundos;(software de programação orientada a objeto, de autoria em multimídia e de educação e entretenimento) .

- Coursewares;(programas educacionais elaborados para o ensino e aprendizagem).

- Tutoriais.

Os mesmos autores ainda apresentam quatro paradigmas educacionais onde o software educacional pode ser inserido:

- Paradigma instrucional (instrução programada, exercício e prática);

- Paradigma revelatório (simulações);

- Paradigma conjectural (modelos);

- Paradigma emancipatório (ferramenta para manipulação de informações, liberando o usuário para concentrar-se na aprendizagem).

Nogueira et al. (2000) criticam a abordagem utilizada pelos softwares educacionais encontrados:

"Analisando os softwares educacionais disponíveis no mercado, pode-se constatar que eles possuem uma importante característica comum: Eles são estáticos, no sentido que independem das concepções do aluno-usuário, ou seja, são preconcebidos de forma a simular situações-problema ou meramente na condição de verificar o acerto ou erro do aluno colocado diante de questões objetivas. Assim, os softwares apresentam as mesmas alternativas para alunos com diferentes graus de desenvolvimento cognitivo e diferentes concepções sobre o tema abordado. Além disso, é claro que os softwares assim concebidos não podem lidar com questões subjetivas, ou seja, com a própria linguagem, concepção e nível cognitivo do aluno, aproximando-se tanto quanto possível da interação professor-aluno na relação ensino-aprendizagem, propiciando uma aprendizagem realmente significativa." 
Os autores sugerem assim que softwares educacionais devem ser baseados em programas de inteligência artificial, com reconhecimento da linguagem, de forma a adequar-se a diferentes usuários/aprendizes, favorecendo desta forma a aprendizagem significativa, onde os conceitos formem relações com outros, e não sejam simplesmente memorizados.

Barreto (2001) considera que são cinco classificações para possíveis usos do computador no ensino:

a) Como máquina de ensinar, seja como tutorial, banco de questões, virador de páginas, instrução programada, ou outro método semelhante. Nesta forma de utilização, não há muita vantagem pedagógica em se usar um computador em detrimento aos métodos tradicionais com lápis e papel, exceto o fator motivacional e a facilidade de uso. Um teste simulado, por exemplo, aplicado por um computador, teria como vantagem sobre um feito no papel, o fato de o aluno não precisar contabilizar manualmente os resultados, o que é muito pouco para justificar por si só o uso de uma máquina (e normalmente um conjunto de programas) de alto custo financeiro. Estes programas podem ser bem mais eficientes se utilizarem inteligência artificial para a tomada de decisões quanto ao que oferecer e cobrar do estudante/usuário.

b) Como ferramenta, tanto burocrática quanto intelectual. Burocrática no sentido de que, por exemplo, o processador de textos é uma ferramenta valiosíssima para professores e alunos, uma vez que os faz ganhar tempo que pode ser utilizado na atividade intelectual, tanto durante a aula, quanto em outros ambientes e horários. Planilhas de cálculo e programas para editoração eletrônica são também exemplos desta forma de utilização da Informática. Como ferramenta intelectual o computador pode ser usado como auxiliar de laboratório, colhendo dados, traçando gráficos, ou resolvendo equações.

c) Como instrumento de programação, sendo assim utilizado de forma a promover a aprendizagem por descoberta. Como exemplo temos o LOGO, e outras linguagens de programação que permitem ao estudante criar processos de resolução de problemas. Vitale apud Barreto (2001) defende que esta forma de utilização é a mais proveitosa, por permitir que os alunos e professores tenham liberdade de criação de softwares, não dependendo exclusivamente de especialistas em Informática para a produção dos recursos utilizados.

d) Em simulações. Podemos ainda dividir as simulações em dois grupos: as estáticas e as dinâmicas. Nas simulações estáticas, o estudante tem pouco ou nenhum controle sobre os parâmetros da simulação. Já nas dinâmicas, estes parâmetros podem ser modificados com um grau de liberdade bem maior, de modo que o estudante possa verificar as implicações de cada variável no resultado do fenômeno estudado, tendo assim maior autonomia, tanto com o professor presente quanto sozinho ou em grupo.

e) O uso da Internet. O uso de hipertextos e páginas da web, por exemplo. O correio eletrônico (e-mail) é outro recurso da internet que tem grande utilidade por facilitar a comunicação entre aluno e professor e entre os estudantes.

\section{3- O que é Inteligência Artificial?}

A Inteligência Artificial (IA) surgiu em 1956, de uma reunião feita nos Estados Unidos que contou com cientistas de várias áreas do conhecimento, todos interessados no mesmo objetivo, no estudo de como poderiam ser criadas máquinas inteligentes, e de como estas afetariam os processos existentes. 
A IA tenta entender o comportamento de entidades inteligentes. Mas, ao contrário da filosofia e da psicologia, que estão mais preocupadas com o estudo da inteligência dentro de um contexto de relações humanas, a IA é mais focada em como essas entidades podem ser criadas e utilizadas para determinados fins.

Sobretudo, deve ser entendida como a criação de sistemas que não possuam somente características procedimentais, tendo também, capacidades de ir além dos processos estabelecidos pelo desenvolvedor humano, aprendendo, se adaptando e tomando decisões.

Portando, a IA tem como objetivo utilizar a inteligência, ou seja, as faculdades de pensar, raciocinar e compreender para auxiliar na tomada de decisões, procurando para isto utilizar princípios da inteligência humana.

\section{4- Sistemas Tutores Inteligentes}

Os sistemas tutores inteligentes são uma composição de diversas disciplinas como psicologia, ciência cognitiva e inteligência artificial. $\mathrm{O}$ objetivo principal destes sistemas é a modelagem e representação do conhecimento especialista humano para auxiliar o estudante através de um processo interativo.

Os Sistemas Tutores Inteligentes, STIs, são evoluções dos sistemas CAI, mas que diferentemente desses, utilizam técnicas de Inteligência Artificial que procuram proporcionar uma experiência customizada de aprendizagem para o estudante, simulando as interações professor-aluno.

Segundo o modelo de Jonassen, um STI deve passar em três testes antes de ser considerado "inteligente" (JONASSEN, 1993):

a) O conteúdo do tema ou especialidade deve ser codificada, de modo que o sistema possa acessar as informações, fazer inferências ou resolver problemas.

b) O sistema deve ser capaz de avaliar a aquisição deste conhecimento pelo estudante.

c) As estratégias tutoriais devem ser projetadas para reduzir a discrepância entre o conhecimento do especialista e o conhecimento do estudante.

Ainda, segundo JONASSEN (1993), a arquitetura de um STI considera quatro componentes, apresentados a seguir:

Modelo do Especialista: Refere-se à base de conhecimento do domínio que deve ser mapeado em forma de símbolos. Deve ser planejado, pelo especialista e pelo projetista do STI, para que sua forma seja bem estruturada facilitando a consulta e a inferência.

Modelo do Estudante: Representa as ações e reações do estudante dentro do STI, mapeando todos os aspectos comportamentais que possam influenciar o processo de aprendizagem. Armazena diversos tipos de informação, como o maior interesse demonstrado pelo aluno entre um ou outro sub-domínio do conhecimento e a velocidade com que essas interações estão sendo feitas dentro do sistema.

Modelo Pedagógico: Refere-se às abordagens usadas pelo sistema para que o processo de aprendizagem ocorra de forma mais proveitosa. Tem na diferença de experiências entre os diversos aprendizes a principal dificuldade para a sua implementação. Deve ser altamente adaptável. (WENGER, 1987)

Modelo da Interface com o Estudante: É a interface utilizada pelo estudante para se comunicar com o STI. Deve ser intuitivo e não oferecer complicadores para a sua 
utilização. Com o avanço das técnicas de processamento de linguagem natural, ganhará mais

usabilidade.

O ensino, por ser uma área que depende da interação e da adaptação, características tipicamente humanas, apresenta muitas dificuldades na implementação de soluções computacionais inteligentes.

\section{5-Inteligência Artificial no ensino com computador} computador.

Existem vários modelos segundo os quais IA pode ser útil no ensino com

\section{1-Segundo o tipo de interação}

As técnicas de Inteligência artificial, proporcionando a possibilidade de dispor de computadores mais autônomos, modifica o tipo de interação homem-máquina, afetando o ensino. Por exemplo, no jogo de xadrez é utilizado técnicas de IA. Os jogos "Wumpus" e "West" reconhecem a qualidade das jogadas e fornecem conselhos para jogar melhor.

O computador permite fazer simulações. E que relação existe entre simulação e inteligência artificial? Segundo Barreto (2001):

- "em simulação trabalha-se com modelos. Modelos são representações do mundo real. Em simulação é importante a escolha do modelo adequado. Em inteligência artificial trabalha-se com modelos de conhecimentos. Os modelos de conhecimentos são representações de conhecimentos reais. Em inteligência artificial é importante a escolha da representação de conhecimentos adequada".

- "A metodologia de trabalho em simulação é inicialmente estabelecer um modelo do fenômeno que se deseja estudar, possivelmente sob a forma de equações matemáticas. Manipular estas equações para obter a resposta. Interpretar a resposta. Em IA a metodologia é diferente, mais direta. Não se passa pelo modelo matemático. Da compreensão do funcionamento do sistema a estudar passa-se por raciocínios, diretamente à interpretação da resposta..

- "Preparação de uma lição: um modo de preparar uma lição é começar por dividir o conhecimento a transmitir em unidades básicas. Cada uma dessas unidades básicas será apresentada como um todo ao aluno. Um modo de ver a estrutura da lição seria como um grafo orientado, em que as páginas ocupam nós e as transições são os arcos. Esse tipo de programa é demorado para preparar e encerra pouca "inteligência", pois todo o comportamento do aluno deve ser previsto na fase da elaboração da lição".

- "Uso da lição: considerando a estrutura de uma lição como resposta acima, uma vez no início da lição, há a possibilidade de receber informação, responder perguntas, em função de eventuais erros receber explicações que podem esclarecer melhor o assunto".

- "Alguns tutoriais de programas de computador permitem uma opção em que se pode experimentar com o programa e voltar ao tutorial. Trata-se de uma combinação de apresentação da matéria com simulação da atividade de programação".(mulisp) 
- "Ainda alguns tutoriais de programas de computador, que apresentam exercícios, permitem um "help" sensível ao contexto do exercício". (lótus)

\section{2-Onde usar IA no ensino?}

Para definir em que campo a IA pode ser usada no ensino, devem-se considerar quais os agentes envolvidos no processo. Os agentes são:

-Que ensinar? A matéria.

-Quem deve aprender? O aluno.

-Quem rege o processo de ensino? O professor.

Segundo Barreto (2001), para cada um desses agentes corresponde um nível de IA. Assim, estes tipos são: o modelo da matéria, o modelo do aluno (o conhecimento do que o aluno sabe e não sabe), e das estratégias de ensino. Cada um destes níveis de possibilidade do uso da IA corresponde a técnicas particulares, e necessidades freqüentemente diferentes, interagindo com diversos campos de conhecimento.

O modelo da matéria motiva estudos dependentes do assunto a transmitir. Assim, para ensinar o funcionamento de um sistema físico é útil o uso da física qualitativa. Sendo o modelo do aluno uma representação dos conhecimentos anteriores do aluno, de suas dúvidas, de seu modo preferencial de aprender, envolve conhecimentos de psicologia e ciência da cognição.

As estratégias de ensino são campo da didática e como tal interage com o assunto a ensinar e com o modelo do aluno. Pela interação com outros assuntos, o uso da IA em ensino torna-se, não somente uma melhor forma de transmissão de conhecimentos, como mola impulsionadora de novas pesquisas.

\section{6-Ensino com computador e Internet}

\section{1-Ferramentas, tarefas e diálogo:}

O desenvolvimento de ambiente computacional para apoio educacional envolve no mínimo três formas: ferramentas, tarefas e diálogo. Em primeiro lugar, deve-se ter acesso a um ambiente satisfatório contendo ferramentas ou recursos necessários para adquirir ou entender os conceitos do domínio. Em segundo lugar, a interação ativa e dinâmica oferecida pelas tarefas permite aos estudantes desenvolver perícias práticas. Em terceiro lugar, o diálogo da interação com o tutor ajuda o estudante a expor as inconsistências do processo de aprendizagem.

As tarefas devem ser designadas para incorporar situações as quais levem os estudantes a um conflito cognitivo e a resolver tais conflitos com capacidades de raciocínio no domínio de desenvolvimento. Os estudantes necessitam experimentar inconsistência e contradição para fazer mudanças significantes no seu modo de interpretar o mundo. Isto implica que as tarefas devam ser estruturadas para conduzir o estudante a situações onde seu conhecimento atual de resolução de problemas é insuficiente. Neste ponto, a interação pode ser importante porque promove o diálogo e a criatividade. Portanto, o professor deve designar não somente tarefas que levem o estudante ao conflito cognitivo, mas também, trazer tal conflito à atenção dos estudantes, ajudando-os a reconhecer o que é necessário para a mudança. O principal é 
que as tarefas devem ser construídas de forma a estimular o diálogo e a auto-crítica. A construção do próprio conhecimento é uma atividade social e não somente uma atividade individual.

As formas corretas de comunicação são importantes para promoção do diálogo. A comunicação humana é entendida como troca de informação que modifica o estado de conhecimento dos parceiros comunicantes, neste sentido, são criados ambientes de comunicação que permitem esta troca de informações. A comunicação educacional especificamente consiste de conteúdos e relações das pessoas participantes no processo educacional. A Internet culmina todas as formas preliminares de comunicação e aumenta as possibilidades do armazenamento de informações e transmissão de conhecimentos.

\section{2-Ambientes distribuídos}

Partindo da hipótese de que através da comunicação mediada por computador o estudante pode construir conhecimento, surgiram diversas formas de uso das redes de computadores na aprendizagem.

A tecnologia de rede de computadores possibilitou a formação continuada de adultos. As redes liberam a aprendizagem das restrições espaciais e temporais. As diferentes interações que um indivíduo necessita vivenciar para que ocorra a aprendizagem podem ocorrer em qualquer lugar e a qualquer momento que o aprendiz se conecte na rede.

Barreto (2001) diz que o ambiente na rede deve ser projetado para integrar mídias diferentes e como a informação recebida é interpretada pelo estudante depende de como ele a vê na tela. E isto depende de como a página Web é construída e como se organiza o conteúdo. $\mathrm{O}$ autor sugere algumas considerações para se criar um ambiente pedagógico:

- o material "on-line" é didático? Deve-se decidir se o conteúdo é satisfatório para um ambiente assíncrono.

- os mecanismos são adequados? Devem-se enfocar as exigências mínimas necessárias em lugar de características tecnológicas que possam diminuir a efetividade e o valor pedagógico. Um site bem projetado pode ser usado como uma boa ferramenta pedagógica sem características desnecessárias.

- como ser criativo no projeto de ambientes "on-line"? Como tirar proveito de ambientes de instrução já construídos? A escolha em adotar produtos prontos ou como colocá-los no site irá depender de quanto material será posto e quanto tempo e dinheiro está disponível.

Barreto (2001) afirma que para oferecer um ambiente de aprendizagem "on-line" existem muitos itens para se pensar. Os principais são:

-Testar extensivamente o site: este ainda em desenvolvimento, deve ser examinado em uma grande variedade de navegadores e sistemas operacionais. Se existir uma aceitabilidade similar na maioria deles, então o código foi bem escrito, em consideração às diferenças inatas entre estes navegadores e sistemas operacionais.

-Estimular a criação de páginas simples e bem projetadas de forma a manter as exibições simples e consistentes. Cabeçalhos, rodapés, menus de páginas e todas as exibições devem estar num projeto consistente. Usar botões comandos e abreviações padronizadas.

V.3 No 1, Maio, 2005 
Fishwick apud Barreto (2001) considera os seguintes pontos na implementação de um site de aprendizagem na Internet:

- Atualização de materiais para manter o interesse dos estudantes e acompanhar a tecnologia. Os próprios estudantes podem ser envolvidos nesta atividade.

- Utilização de modelos padrões para economizar tempo e prover um banco de diferentes modelos para vários tipos de páginas.

- Facilidade de impressão, compactação e obtenção da documentação.

- Verificação da disponibilidade da informação necessária para evitar a frustração do estudante.

- Consistência nos sinalizadores de informações úteis (marcadores no topo das páginas oferecem rápido acesso) na páginas,

- Simplicidade e clareza das páginas: em ambientes hipertexto, estudantes podem ir a toda parte e se perdem também. Deve-se ter certeza que vínculos de hipertexto não sejam exagerados. Só devem ser usados quando forem essenciais.

- Espaçamento das páginas: as páginas não devem sobrecarregar os estudantes com muita informação simultânea.

- Edição cuidadosa: verificações devem ser feitas quanto à linguagem utilizada, ortografia e gramática para evitar confusões.

- Inclusão de áudio com tons suaves, os vídeos devem ser usados quando uma técnica de movimento é essencial. A imagens são mais efetivas. A tendência é utilizar animações Java que requerem menos recursos computacionais $\mathrm{e}$ produzem bons efeitos.

- Ferramentas de apoio à navegação.

\section{3-Ajuda ao usuário}

O ambiente deve conter ajuda a todas as operações efetuadas pelo usuário com documentação "on-line".

Outro procedimento pode ser a colocação de exemplos elucidativos para auxiliar o aprendiz. Uma boa opção é colocar um módulo de ajuda sensível ao texto para as questões que podem surgir como o manuseio do programa, a introdução de parâmetros, a verificação das respostas e os resultados gráficos. A produção de ligações (links) com páginas de ajuda será facilitada pela abordagem hipertexto, mas deve ser observado o perigo da perda no espaço de informações.

\section{7-Considerações sobre a linguagem de implementação}

Um dos problemas das programações educacionais é a diversidade de domínios, situações, condições estratégias, etc, em que podem ser utilizados. Isto dificulta a especificação de uma ferramenta para construir este tipo de programas. A ferramenta para apoiar o ensino deve:

- ser especificamente desenvolvida para este fim e possibilitar a construção de programas de simulação com diferentes tipos de modelos. 
- permitir a colocação de diversas formas de visualização variadas e técnicas de animação diversas.

- permitir a inclusão de diversas formas de interação (botões, menus, ícones, janelas, caixas de diálogo, perguntas de escolha múltipla,...)

- integrar outros meios no programa (som, imagens digitalizadas,...) e dados de outras ferramentas se possível.

- ser de fácil manuseio, permitindo alterações sempre que for necessário.

- ser portável, para outras máquinas, línguas e culturas e permitir a utilização, individual ou em rede, e ser barata.

\section{8-Construção de um ambiente para aprendizagem de trigonometria}

A construção de um ambiente de aprendizagem, cujo domínio de conhecimento é de uma parte da matemática chamada trigonometria, deve constar os seguintes passos:

- Introdução e Motivação: deve descrever o objetivo de trabalhar com trigonometria; a origem da palavra trigonometria; colocar figuras sobre trigonometria, colocar som.

- Histórico: mostrar como iniciou o estudo de trigonometria, onde ela foi usada, descrever todo o histórico da trigonometria, desde sua invenção para uso nas grandes navegações até seu uso nos nossos dias.

- Técnicas de aprendizado: usar técnicas de aprendizado dos tipos: aquisição direta de novo conhecimento (formar uma biblioteca com todo o assunto de trigonometria); aprendizado por descoberta (associação entre um conceito novo "trigonometria" e um conhecido "geometria básica"); aprendizado baseado em explicações( generalizar a explicação para concordar com a teoria); aprendizado por exemplos (aprendizagem de conceitos a partir de exemplos).

\section{-Arquitetura do Componente de Aprendizado:}

- Elemento de aprendizado: montar uma biblioteca de conteúdo e exercícios de trigonometria ou de situações onde aparece algum conceito de trigonometria;

- Avaliação de desempenho e seleção de ações externas: construir um agente inteligente cuja função é monitorar as ações do estudante e atuar dinamicamente, durante a tentativa do aluno para resolver um exercício ou para auxiliá-lo na resolução de um problema ;

- Crítica: construir um agente cuja função é direcionar os estudos do aluno; dizendo se o aluno está certo ou errado; fazendo sugestões, fazendo elogios;

- Gerador de problemas: construir um agente que indique a seqüência de exercícios apropriada a cada passo, o nível de dificuldade, áreas de aplicações;

- Feedback: para reforçar o aprendizado, construir uma interface para a visualização de exercícios resolvidos, onde o estudante comanda, passo-apasso, a execução da solução do exercício que aparece na forma de animação, ao mesmo tempo em que uma janela de texto apresenta uma explicação sobre cada etapa da solução. 


\section{9-Conclusão:}

As estratégias de ensino fazem com que exista interação com o assunto a ensinar e com o modelo do aluno. Pela interação com outros assuntos, o uso da IA em ensino torna-se a melhor forma de transmissão de conhecimentos e, ainda, a motivação de novas pesquisas.

Além disso, há necessidade de desenvolver novas ferramentas que possam ser integradas para alcançar diversos princípios pedagógicos. Estas ferramentas deveriam, além de permitir a cooperação dos estudantes durante a resolução de problemas, oferecer orientação e informações adicionais. Também é importante que uma ferramenta voltada ao ensino permita o aprendizado de forma assíncrona, onde o estudante possa criar sua própria programação, mas ainda permitindo a colaboração. Serviços adicionais como busca de informação automatizada, salas de discussão e correio eletrônico orientado também deveriam ser incorporados. O objetivo é fazer com que o estudante faça uma imersão durante o tempo em que estiver utilizando a ferramenta.

Atualmente as pesquisas em ambientes de ensino-aprendizagem, preocupam-se com a construção de ambientes que possibilitem um aprendizado mais eficiente. A tecnologia dos agentes tornou os Sistemas Tutores Inteligentes mais adaptados às necessidades e características individuais de cada estudante. A interação entre estudante e tutor tenta se aproximar cada vez mais da interação estudante professor tornando o sistema uma extensão da sala de aula e fazendo com que esta interação ocorra de maneira mais natural possível.

\section{0-Referências Bibliográficas:}

-BARRETO, J.M. Inteligência artificial no limiar do século XXI. Florianópolis, o autor, 2001.

- BONILlA, Maria Helena S. Concepções do Uso do Computador na Educação. Espaços

da Escola, Ano 4, No. 18 (59-68). Ijuí: 1995.

-BRANDÃO, Edemilson Jorge Ramos. Construção de modelos de avaliação de software

educacional. Seminário de Pesquisa em Educação da Região Sul. Florianópolis: 1998.

-GIRAFFA,L.M.M. Uma arquitetura de tutor utilizando estados mentais. Porto Alegre:CPGCC-UFRGS, 1999. Tese de doutorado.

-JESUS, Andréia de . Sistemas tutores inteligentes, uma idéia geral. www.presidentekennedy.br/resi/edico03/artigo.pdf. Acessado em 10/12/2004.

- JONASSEN D. H. The Physics Tutor: Integrating Hypertext and Expert Systems, Journal of Educational Technology Systems, (s.1.), vol. 22, n. 1, 1993. 
- NOGUEIRA, José de Souza, RINALDI, Carlos FERREIRA, Josimar M. e PAULO,

Sérgio R. de. Utilização do Computador como Instrumento de Ensino: Uma Perspectiva de Aprendizagem Significativa. Revista Brasileira de Ensino de Física, vol. 22, n. 4 (517-522). São Paulo: 2000.

- OLIVEIRA, Ramon de. Informática Educativa: dos planos e discursos à sala de aula.

- ROCHA, Ana Regina e CAMPOS, Gilda H Bernardino. Avaliação da qualidade de software educacional. Em Aberto, ano 12, n.57. Brasília: 1993.

Papirus. São Paulo: 1997.

-WENGER, E., "Artificial Intelligence and Tutoring Systems", Morgan Kaufmann Publishers, Inc., 1987.

-VALENTE, José Armando. Diferentes usos do computador na Educação. Em Aberto,

Ano 12, no. 57 (3-16). Brasília: 1993. 